\title{
Adenovirus behavior in air handling unit fiberglass filters
}

\author{
Victor Bandaly (D) A Aurélie Joubert • Yves Andres • Pierre Le Cann
}

Received: 17 April 2018/Accepted: 19 January 2019/Published online: 4 February 2019

(C) Springer Nature B.V. 2019

\begin{abstract}
Viral aerosols can lead to respiratory viral infections with high infectivity. About $90 \%$ of people's time is spent in closed environments. A few studies have pointed out that the ventilation systems in air handling units (AHUs) that treat and transmit a new synthetic clean and conditioned environment can also spread and transport viral particles in buildings. The aim of this work is to study the characterization of adenovirus, a DNA non-enveloped respiratory virus, on the F7 fiberglass filter used in AHUs. In this study, an experimental setup simulating an AHU was used. The SYBR ${ }^{\circledR}$ QPCR, Electrical Low-Pressure Impactor $\left(\mathrm{ELPI}^{\mathrm{TM}}\right)$ and Scanning Mobility Particle Sizer $\left(\mathrm{SMPS}^{\mathrm{TM}}\right)$ were used to detect, measure and characterize the aerosolized adenovirus solution. The characterization results showed that the nebulized adenovirus could be aerosolized in different forms associated or not with cell debris and proteins. The quantification and level of infectivity of adenovirus demonstrated that viruses passed through filters and remained infectious up- and downstream of the system
\end{abstract}

V. Bandaly $(\bowtie) \cdot$ A. Joubert · Y. Andres GEPEA-CNRS, UMR 6144, IMT Atlantique, 44000 Nantes, France

e-mail: victor.bandaly@mines-nantes.fr

V. Bandaly $\cdot$ P. Le Cann

EHESP, 35000 Rennes, France

V. Bandaly · P. Le Cann

IRSET-INSERM UMR 1085, 35000 Rennes, France during the 25 min of aerosolization. This study showed that AHUs should be considered an indoor source of viral contamination.

Keywords Indoor air quality - Fiberglass filter . AHU · Bioaerosols · Adenovirus · Viral airborne characterization

\section{Introduction}

From the megalopolis to the individual level, the effects of air pollution are of particular interest. Urban air quality and indoor air pollution, which can lead to human health problems, are the most important topics occupying health authorities. According to the study of Jones (1999), indoor air is 5-10 times more polluted with volatile organic compounds (VOCs) than outdoor air. Bioaerosols are airborne particles that originate from living organisms including microorganisms. Different types of microorganisms have been identified as potential contaminants in indoor air, such as spores, bacterial cells and viruses (Douwes et al. 2003). Indeed, in industrialized countries, people spend $90 \%$ of their time in enclosed or semi-enclosed spaces such as homes, offices, shopping centers, gymnasiums and transportation (Aritake et al. 2004; Siegel 2003; Turcotte 2005; Klepeis et al. 2001). Bioaerosols, more specifically viral aerosols, lead to 
diseases and represent a real challenge for the near future because of their high contagiousness. Viral aerosols can be transmitted by simple direct contact, droplets or aerosols. They can cause anything from an ordinary viral infection to an epidemic outbreak (Tellier 2006).

Large numbers of buildings, particularly office buildings, use heating, ventilation and air-conditioning (HVAC) systems. These systems treat and transmit new air with temperature $(T)$ and relative humidity (RH) regulation and a decrease in the particle concentration from the outside air (Seppänen and Fisk 2004). Heating, cooling, humidification and filtration are the different steps performed by air handling units (AHUs) to recondition the air. AHUs should be wellmaintained, contributing to good health and productivity. Filter efficiency is defined according to two main standards (EN779 2012; EN1822 2009), which describe medium-, high- and very high-efficiency filters. Filters are composed of fiber clusters (felts, mats, glass and papers), and their efficiency is characterized by four different mechanisms: sieving, inertia, interception and diffusion (Bailly 2001).

In general, we expel by simply breathing, coughing, and sneezing (Morawska 2006). Different studies have pointed out the number of viral particles exhaled during a single breath, sneeze or cough. For influenza viruses, an infected person can exhale 3-20 viruses per minute (Fabian et al. 2011). A person infected with Coxsackievirus (a pathogenic enterovirus) can emit 160 viral particles when sneezing and coughing (Couch et al. 1966; Downie et al. 1965). The same studies showed that two infected people breathing in an office without sneezing or coughing could emit 20 viruses per minute, corresponding to 0.24 viruses per liter of air (without renewal of air in an office of $40 \mathrm{~m}^{3}$ ) (Couch et al. 1966; Downie et al. 1965). The results of the study by Miller et al. (2017) showed that fine particulate matter (PM) indoors in mechanically ventilated buildings comes from outside. The study of Zhao et al. (2015) evaluated 11 classifications of HVAC filters (MERV5 to HEPA) and ventilation systems located in 22 US cities and demonstrated that higher efficiency HVAC filters are likely to decrease premature mortality, increase life expectancy and yield monetary benefits in all of the homes and locations investigated herein. Some other studies have demonstrated that filters in the ventilation systems can be a source of microbial air pollution and that the ventilation systems and AHUs can spread and transport viral particles inside buildings (Ezratty and Squinazi 2008; Fabian et al. 2008; Tang et al. 2006; Bluyssen et al. 2003). Some recent studies have detected airborne viruses such as picornavirus, corona virus and parainfluenza virus on AHU filters (Myatt et al. 2004; Goyal et al. 2011; Prussin et al. 2016). The persistence of the viral particles can be affected by the temperature and relative humidity $(\mathrm{RH} \%)$ in the AHU. The persistence of influenza viruses increases with decreasing temperature and humidity (Lowen et al. 2007). The review of Gerba (2013) revealed differences in inactivation between enveloped and nonenveloped respiratory viruses, with non-enveloped respiratory viruses surviving longer. The fate of mengovirus, a virus whose structure is close to rhinovirus, on the fiberglass filter of an AHU was studied by Bandaly et al. (2017), who showed that the mengovirus passed through the filter and remained infectious for up to $10 \mathrm{~h}$ up- and downstream of the system.

Concerning bioaerosols in AHUs, few studies have investigated the fate of viral aerosols on the filter. This work aimed to study the fate of adenovirus serotype 2 in an experimental setup representative of AHU. Adenovirus is a DNA human virus of the Adenoviridae family. This respiratory virus presents a spherical 70- and 90-nm-diameter particle (Doerfler 1996) with an adenovirus infective dose equivalent to five viral particles for an adult responsible for pneumonia, angina and bronchitis (Musher 2003). As we had already assessed the fate of mengovirus, a surrogate of a respiratory virus, we wanted to study the fate of a real respiratory virus in an AHU such as adenovirus. Therefore, the adenovirus behavior was explored upand downstream of the fiberglass filter used in the AHU. The virus was characterized and quantified, and the analyses reviewed the performance of fibrous media in decreasing the risk of viral spread in a closed atmosphere and providing good indoor air quality and living conditions even with recycled indoor air.

\section{Materials and methods}

2.1 Viral and cell models

Human adenovirus serotype 2 strain [Health Protection Agency Culture Collections (HPACC); reference 
no. NCPV213] was used throughout this study. Human embryonic kidney cells, type HEK-293, enabled the replication of adenovirus. HEK-293 cells were grown in Dulbecco's Modified Eagle's Medium (DMEM), high glucose, GlutaMAX ${ }^{\mathrm{TM}}$ Supplement (Thermo Fisher Scientific, Waltham, MA, USA) supplemented with $10 \%$ fetal calf serum (F2442, Sigma-Aldrich, St Louis, MO, USA), $1 \%$ non-essential amino acid $(\times 100)($ M7145, Sigma-Aldrich) and $1 \%$ antibiotic-antimycotic $(\times 100)$ (A5955, Sigma Aldrich) at $37{ }^{\circ} \mathrm{C}$ under an atmosphere enriched with $5 \% \mathrm{CO}_{2}$. The average initial concentration of the adenovirus in the suspension is up to $6 \times 10^{6} \mathrm{TCID}_{50}$.

\subsection{Characteristics of the filter media}

The F7 filter (Camfil Farr, Stockholm, Sweden), in compliance with the EN 779 standard (2012), is a high-efficiency filter commonly used in AHUs and so was chosen for this study. It is made of fiberglass felt. The median fiber diameter is $1 \pm 0.2 \mu \mathrm{m}$ (González et al. 2016). The nominal filtration velocity recommended by the manufacturer is $0.2 \mathrm{~m} \mathrm{~s}^{-1}$. The filter was implanted in flat geometry in this study with a filtration area of $17.72 \mathrm{~cm}^{2}$ (circular).

\subsection{Experimental setup and validation (Fig. 1)}

The experimental design consisted of a vertical column made of polymethyl methacrylate where the viruses were aerosolized and homogenized in the upward air flow. This aerosolization was carried out by the medical nebulizer (Omron C29-CompAir Pro, Hoofddorp, The Netherlands), which ensures an air flow of $4.51 \mathrm{~min}^{-1}$ supplied by compressed air. At the upper side of the cylinder, four circular outputs of $4 \mathrm{~cm}$ diameter, which accommodate the filters, are arranged perpendicular to the flow. Three of the four outputs are equipped with the filter to be studied. The fourth output results were used to calculate the number of viruses that theoretically impacted on filters. Downstream of the filters, the BioSampler (SKC Inc., Eighty Four, PA, USA) samples the particles passing through the filters. The sampling rate is 13 $1 \min ^{-1}$ at the entry of each BioSampler. Two volumetric pumps are set downstream of the device to ensure the flow of treated air through the filters. The frontal filtration velocity at each filter is $0.16 \mathrm{~m} \mathrm{~s}^{-1}$ and is representative of the velocity observable in the AHUs on a pleated F7 filter. The device is positioned under a laminar flow hood with clean and sterile air (Fig. 1) (Bandaly et al. 2017).

To monitor the number of generated particles and to determine the global setup performance at each of the
Fig. 1 Description of the experimental setup (Bandaly et al. 2017)

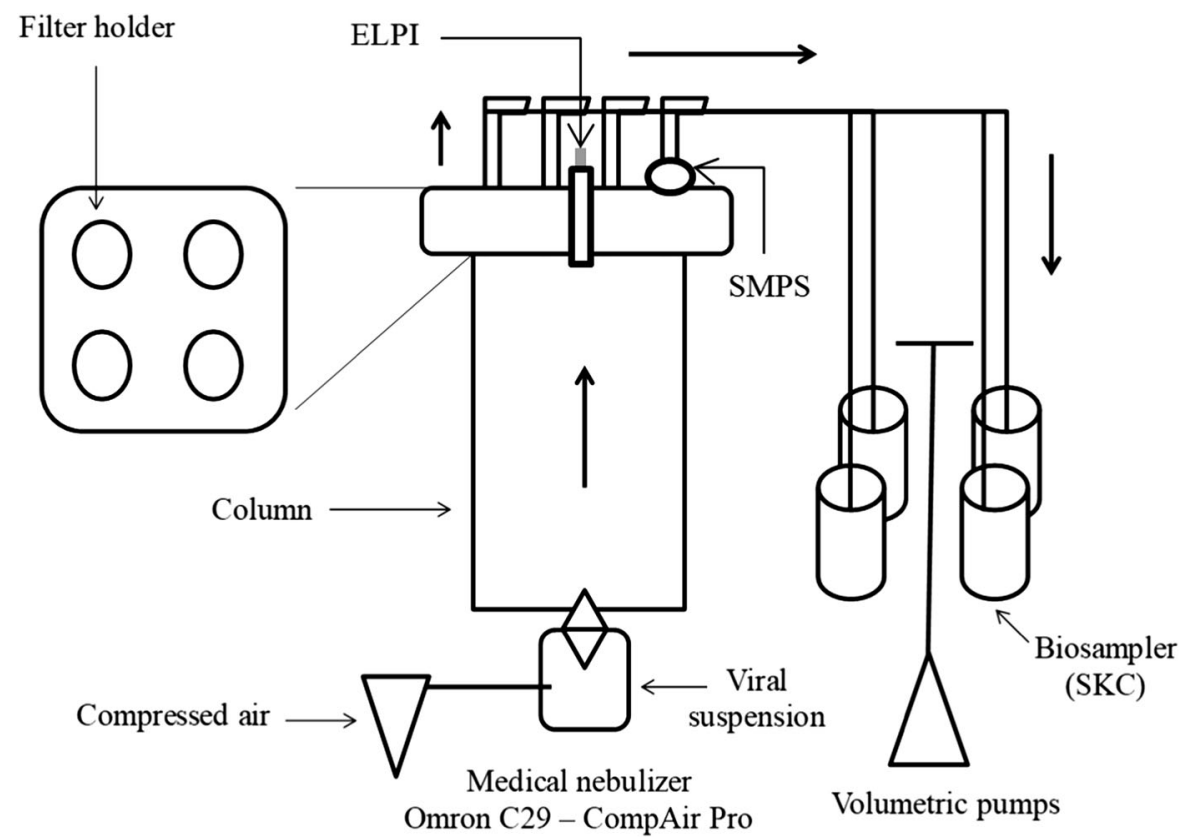


four filter gates, a fluorescein (CAS no. 518-47-8, Merck KGaA, Darmstadt, Germany) solution was generated for $25 \mathrm{~min}$ by the medical nebulizer through the filter device, with or without a filter. The absorbance $(\lambda=470 \mathrm{~nm})$ was measured in the sample from the BioSampler and the liquid extracted from the filters. According to Bandaly et al. (2017), the setup has an efficiency of $76.3 \% \quad(0.58 \mathrm{mg}$ fluorescein collected from an initial solution of $0.76 \mathrm{mg}$ aerosolized).

While aerosolizing the medium without virus for $25 \mathrm{~min}$, the temperature and $\mathrm{RH} \%$ were measured in the setup at the filter level. The temperature remained stable at $16{ }^{\circ} \mathrm{C} \pm 2{ }^{\circ} \mathrm{C}$. The $\mathrm{RH} \%$ increased to $80 \%$ after 3 min of aerosolization, reaching a maximum of $89 \%$ in $14 \mathrm{~min}$. After $20 \mathrm{~min}$, it decreased to $59 \%$ to achieve $52 \%$ after $25 \mathrm{~min}$ of aerosolization (Bandaly et al. 2017).

\subsection{Characteristics and efficiency of the BioSampler}

The principle of the BioSampler (SKC Inc., Eighty Four, PA, USA) is to act as a particle collector. The respirable and non-respirable particles are separated by the curved inlet tube simulating the entry of air through the nasal passage. DMEM was the medium used to collect the particles from the air in the setup to put the viruses directly in the right conditions to be infective; $20 \mathrm{ml}$ DMEM avoided liquid evaporation with a flow rate of $131 \mathrm{~min}^{-1}$ for $15 \mathrm{~min}$ (Faure 2010). The efficiency of the BioSampler changes according to the size of the particles: $>50 \%$ for particles $>$ $0.03 \mu \mathrm{m},>80 \%$ for particles between 0.5 and $1 \mu \mathrm{m}$ and $>95 \%$ for particles $>1 \mu \mathrm{m}$ (Zheng and Yao 2017). Samples of the collected liquid can be analyzed.

\subsection{Preparation of the aerosolized virus suspension}

The fragility of the adenovirus was taken into consideration; the virus was obtained directly from the culture solution after multiplication in HEK-293. Centrifugation of the culture at $1750 \times g$ for $10 \mathrm{~min}$ removed cell debris. The supernatant was collected to be aerosolized.

\subsubsection{Aerosol characterization}

The Electrical Low Pressure Impactor (ELPI $^{\mathrm{TM}}$, Dekati, Kangasala, Finland) and the Scanning Mobility Particle Sizer (SMPS $^{\mathrm{TM}}$, GRIMM, Ainring, Germany) were used to analyze the aerosol size. These two instruments can characterize the aerosol size in different ways. The aerodynamic size of particles from $7 \mathrm{~nm}$ to $4 \mu \mathrm{m}$ was characterized by the ELPI ${ }^{\mathrm{TM}}$, and the electrical mobility size of particles from $10 \mathrm{~nm}$ to $1 \mu \mathrm{m}$ was characterized by the SMPS ${ }^{\mathrm{TM}}$. The special feature of ELPI ${ }^{\mathrm{TM}}$ is that the particles deposed on the various stages can be detected by molecular methods (Q-PCR). The SMPS ${ }^{\mathrm{TM}}$ samples are collected from the top and center of the column, and the ELPI ${ }^{\mathrm{TM}}$ samples are collected from the output without a filter.

\subsection{Extraction, primers, probes and molecular assays}

The NucliSens ${ }^{\circledR}$ easyMAG ${ }^{\mathrm{TM}}$ Platform (Biomérieux, Marcy l'Etoile, France) was used to extract the adenovirus DNA. Adenovirus was quantified using a real-time SYBR green PCR carried out with the Brilliant III Ultra-Fast SYBR ${ }^{\circledR}$ QPCR Mix kit (Agilent Technologies, Santa Clara, CA, USA) with the reverse primer AdF1B (5'-GGA-YGC-YTC-GGA-GTACCT-GAG-3') and the forward primer AdR2B (5'ACS-GTG-GGG-TTY-CTA-AAC-TTG-TT-3') (Ryu et al. 2015). The SYBR green Q-PCR program was as follows: $3 \mathrm{~min}$ at $95^{\circ} \mathrm{C}$ for enzyme activation, 40 cycles of $20 \mathrm{~s}$ at $95{ }^{\circ} \mathrm{C}$ for denaturation and $20 \mathrm{~s}$ at $58{ }^{\circ} \mathrm{C}$ for annealing-extension. This was achieved on an Agilent MXPRO3005P PCR platform (Agilent Technologies). The DNA extract of adenovirus was used as the PCR-positive control. For this study, two PCR-negative controls were approved: the water used in the Brilliant III Ultra-Fast SYBR ${ }^{\circledR}$ QPCR Mix and the DMEM used for culture. Adenovirus was quantified by the standard curve, based on the calibration of the virus initial solution. The melting curve was used as a quality control of the specificity of the method.

\subsubsection{Tissue culture infective dose test $\left(T C I D_{50}\right)$ (determination of adenovirus infectivity)}

To determine the adenovirus infectivity up- and downstream of the system, the $\mathrm{TCID}_{50}$ test was used. It was carried out on HEK-293 cells seeded in 96-well 
plates, infected with serial dilutions of the sample and then incubated at $37{ }^{\circ} \mathrm{C}$ with $5 \% \mathrm{CO}_{2}$ for $48 \mathrm{~h}$. The positive wells in the plates, showing the apoptotic effect, were counted under a microscope. Using the Spearman-Karber statistical method, the infectivity of the virus was calculated (Ramakrishnan 2016).

\subsection{Extracting viruses from the tested F7 filter}

The filters were washed in $20 \mathrm{ml}$ preheated DMEM with stirring at $250 \mathrm{rpm}$ for $30 \mathrm{~min}$ in two stages. After centrifugation, the supernatant was recovered and treated with chloroform. This step removes all contaminant microorganisms such as bacteria and fungi. The same extraction was carried out on a virgin filter to confirm that there was no adverse effect of the filter on the HEK-293 cells when using the TCID $_{50}$ test. Adenovirus was quantified per genomic unit (GU) on a filter to test the loss of quantity by using this extraction method; from $3.24 \times 10^{5} \mathrm{GU} \mathrm{cm}^{-2}$ of adenovirus theoretically deposited on the filter, $2.43 \times 10^{5} \mathrm{GU} \mathrm{cm}^{-2}$ was detected by Real-Time PCR based on SYBR-Green. This indicates a loss of $0.12 \log$ of virus, giving a yield of $75 \%$ for this extraction method.

\subsection{Normalization results}

The quantification and infectivity of the virus were normalized by the volume of air and the area of the filter.

For the initial solution, the results were normalized per cubic meter of air volume passed through the four outputs in the system, equal to $1.3 \mathrm{~m}^{3}$ of air during the $25 \mathrm{~min}$ of aerosolization. Each output related to the BioSampler represents $0.325 \mathrm{~m}^{3}$ of air volume passed during the $25 \mathrm{~min}$ of aerosolization.

For the adenovirus quantification or infectivity on the filters, the results were normalized by the filter area equal to $17.72 \mathrm{~cm}^{2}$.

To compare the quantification with the infectivity of the adenovirus, the result of infectivity $\left(\right.$ TCID $\left._{50}\right)$ should be converted to the plaque-forming unit (PFU) where $1 \mathrm{TCID}_{50}$ is equal to $0.69 \mathrm{PFU}$.

\section{Results}

\subsection{Characterization of adenovirus aerosol}

Figures 2 and 3 present the ELPI ${ }^{\mathrm{TM}}$ and SMPS ${ }^{\mathrm{TM}}$ particle size distribution measurement of the adenovirus suspension aerosolized by the medical nebulizer. The median aerodynamic size $\left(d_{\text {ae.50 }}\right)$, calculated from the ELPI ${ }^{\mathrm{TM}}$ polydisperse particles is $110 \mathrm{~nm}$ (Fig. 2). The SMPS ${ }^{\mathrm{TM}}$ polydisperse particle size distribution measurement presents a median electric mobility size $\left(d_{\mathrm{ae} .50}\right)$ of $87 \mathrm{~nm}$ (Fig. 3). The ELPI ${ }^{\mathrm{TM}}$ collected the particles at different stages, and these were extracted in DMEM. Detection and quantification of the virus were carried out by SYBR green Q-PCR. Based on the concentration of nebulized virus in the initial solution, the virus was quantified at the various stages. Different quantities of adenovirus were detected in all the collected fractions. The largest amount measured between 382 and $1600 \mathrm{~nm}$, while the smallest quantity (negligible) was detected at the stages representing a size $<56 \mathrm{~nm}$ (Fig. 4). The error deviation in the figures is based on 1100 samples (1 measure per second during an 18-min period).

3.2 Detection and quantification of adenovirus upstream, downstream and on the filters in the experimental setup

Based on the $\mathrm{SYBR}^{\circledR}$ QPCR measurement, the adenovirus recovered in the system (filters and BioSampler) and the total initial output aerosolized

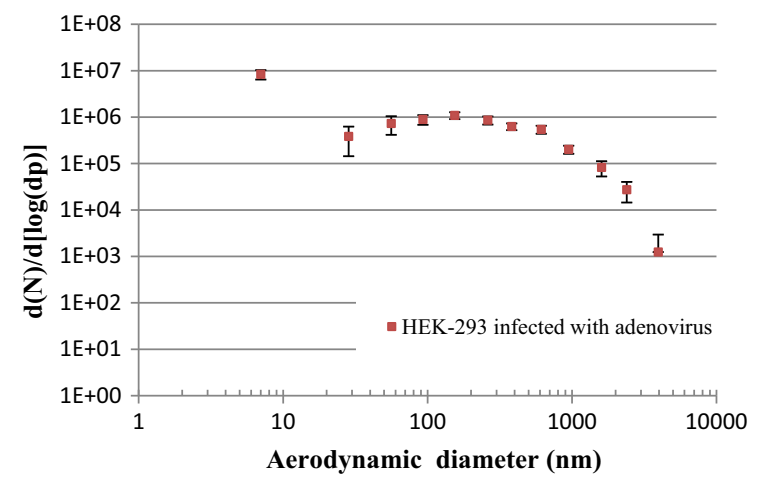

Fig. 2 ELPI $^{\mathrm{TM}}$ particle size distribution measurement of the adenovirus suspension aerosolized by the medical nebulizer $[\mathrm{d}(\mathrm{N})=$ number of particles; $\mathrm{dp}=$ particle diameter $]$. The error deviation in the figures is based on 1100 samples (1 measure per second during an 18-min period) 


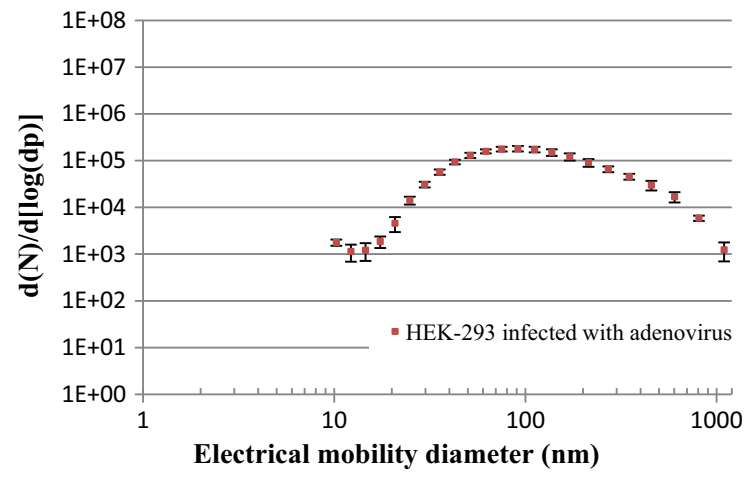

Fig. 3 SMPS $^{\mathrm{TM}}$ particle size distribution measurement of the adenovirus suspension aerosolized by the medical nebulizer $[\mathrm{d}(\mathrm{N})=$ number of particles; $\mathrm{dp}=$ particle diameter $]$. The error deviation in the figures is based on 1100 samples ( 1 measure per second during an 18-min period)

were measured. The F7 filter efficiency was calculated by comparing viruses recovered on the filter and adenovirus quantity downstream of the system in the absence of a filter. The filter F7 efficiency was between 91 and $99 \%$. With reference to the study of the efficiency curves of the filtration carried out by González et al. (2016), the F7 showed efficiency between 80 and $90 \%$ for particle diameters equal to $0.4 \mu \mathrm{m}$, and it increased with particle diameters $<$ $0.4 \mu \mathrm{m}$. Comparing the present virus size, the experimental setup shows consistent filtration performance.

The average quantification of two experiments showed that from an initial solution of $3.99 \times 10^{6} \mathrm{GU}$ aerosolized for $25 \mathrm{~min}, 2.84 \times 10^{6} \mathrm{GU}$ of adenovirus was collected on the three filters, and $1.06 \times 10^{5} \mathrm{GU}$ passed through them. BioSampler no. 4, the output without a filter, collected $8.56 \times 10^{5}$ GU (Table 1). Comparing this quantity to the initial concentration aerosolized, there was a loss of $0.67 \mathrm{log}$ of adenovirus in the system. The fluorescein validation carried out in the study of Bandaly et al. (2017) demonstrated that this loss is attributed to the non-recovered virus present on the column and the pipes. After $25 \mathrm{~min}$ of aerosolization, a few microliters of adenovirus remained in the medical nebulizer. Comparing the concentration of the initial solution and the rest of the Omron, no concentration effect was observed during aerosolization (data not shown).

\subsection{Adenovirus infectivity in the experimental setup (upstream, downstream and on the filters)}

The infectivity levels of adenovirus showed that $5.94 \times 10^{6}$ TCID $_{50}$ of infectious adenovirus was aerosolized upstream of the system, and $2.27 \times 10^{5}$ TCID $_{50}$ was collected downstream of the system in the absence of a filter; $1.41 \mathrm{log}$ of adenovirus infectivity was lost during the aerosolization (Table 1). This result demonstrates an effect of aerosolization on the virus infectivity. According to the TCID $_{50}$ test, about 500 adenoviruses that passed downstream of the system remained infectious, and $5.79 \times 10^{3}$ TCID $_{50}$ was recovered on the total of filters 1,2 and 3 . The adenovirus left in the medical nebulizer after
Fig. 4 Adenovirus detection and quantification at each ELPI ${ }^{\mathrm{TM}}$ stage. The error deviation in the figures is based on 1100 samples (1 measure per second during an 18-min period) with two qPCR replicates

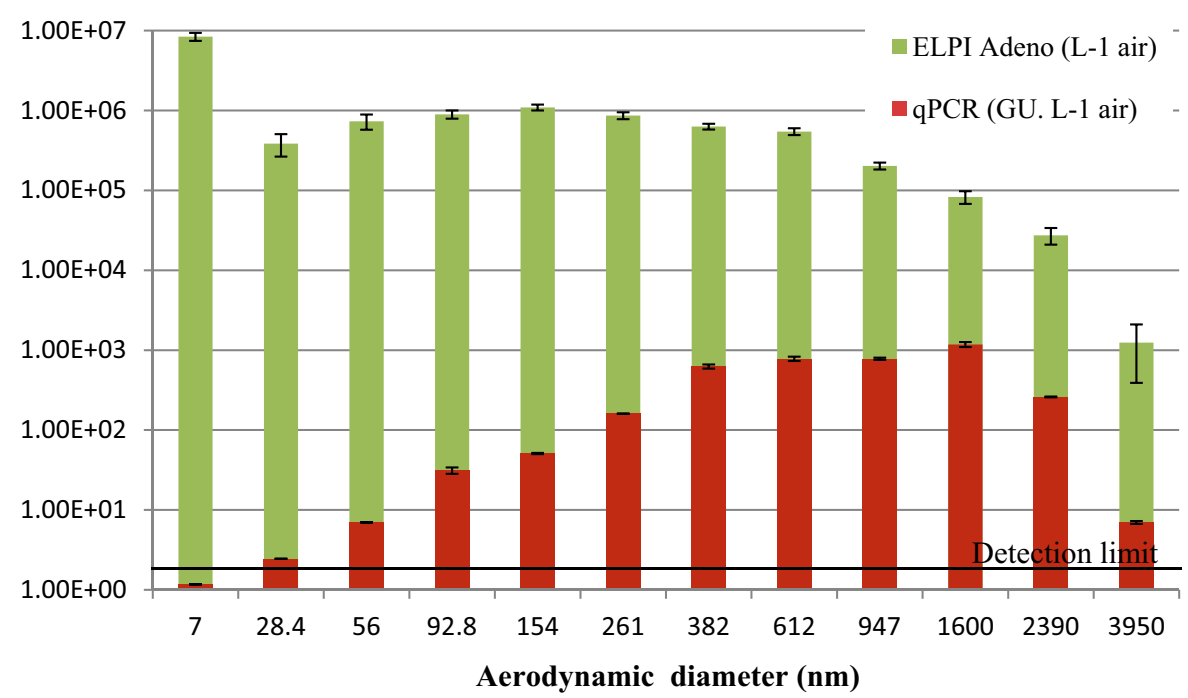


Table 1 Average quantification and infectivity detection of the initial aerosolized viral suspension, samples from BioSamplers and the virus extracted from filters by $\mathrm{SYBR}^{\circledR}$ QPCR measurement (GU) (quantification) and TCID measurement (infectivity detection) normalization of the virus detection by volume of air and area of the filter

\begin{tabular}{lcc}
\hline Average & Quantity $(\mathrm{GU})$ & Quantity $\left(\mathrm{TCID}_{50}\right)$ \\
\hline Initial viral suspension & $3.99 \times 10^{6}$ & $5.94 \times 10^{6}$ \\
Filter 1 & $7.91 \times 10^{5}$ & $2.18 \times 10^{3}$ \\
Filter 2 & $9.9 \times 10^{5}$ & $1.61 \times 10^{3}$ \\
Filter 3 & $1.06 \times 10^{6}$ & $2 \times 10^{3}$ \\
BioSampler 1 & $4.31 \times 10^{4}$ & $1.33 \times 10^{2}$ \\
BioSampler 2 & $2.67 \times 10^{4}$ & $1.84 \times 10^{2}$ \\
BioSampler 3 & $3.65 \times 10^{4}$ & $1.94 \times 10^{2}$ \\
BioSampler 4 & $8.56 \times 10^{5}$ & $2.27 \times 10^{5}$ \\
\hline
\end{tabular}

aerosolization remained infective. Comparing the remaining virus in the Omron with the initial solution aerosolized, no loss of infectivity of adenovirus was detected (data not shown).

\subsection{Adenovirus infectivity versus quantification} (Fig. 5)

To compare the quantification and infectivity of adenovirus on filters or in the BioSampler, the adenovirus collected was quantified by PCR (GU), and infectivity was assessed using the plaque-forming unit (PFU) (1 TCID = 0.69 PFU). The determination of adenovirus infectivity is an estimate calculated using the Spearman-Karber statistical method.

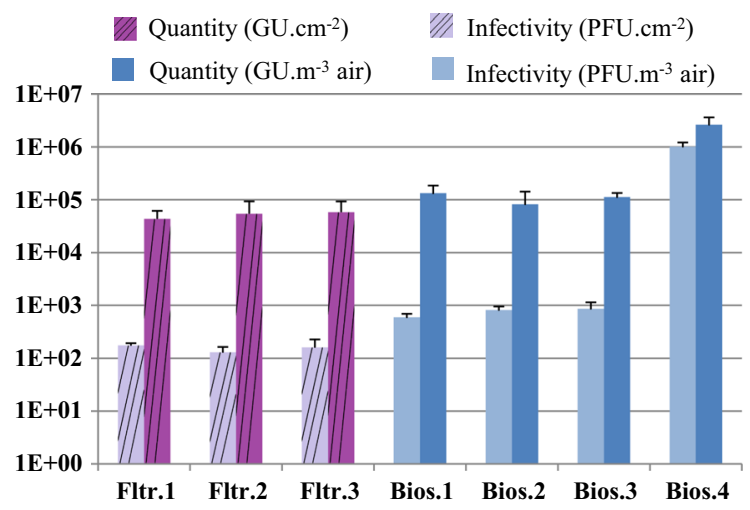

Fig. 5 Infectivity and quantification comparison of adenovirus downstream of the system and on the filters (average of 2 experiments)
The quantification and infectivity of the virus were normalized by the volume of air and the area of the filter. The adenovirus infectivity and quantification were measured for the output without a filter and showed $2.63 \times 10^{3} \mathrm{GU} \mathrm{m}^{-3}$ air, of which $1.01 \times 10^{3}$ PFU m ${ }^{-3}$ was infectious. Therefore, $0.42 \log$ of adenovirus lost infectivity during the $25 \mathrm{~min}$ of aerosolization. Comparing the adenovirus infectivity and quantification on the filters, $1.61 \times 10^{5} \mathrm{GU} \mathrm{cm}^{-2}$ was detected, of which $4.74 \times 10^{2} \mathrm{PFU} \mathrm{cm}^{-2}$ remained infectious; thus, $2.5 \log$ of virus lost infectivity. In the BioSamplers, $3.3 \times 10^{5}$ viruses were detected per cubic meter of air passed through the filters, of which $1.6 \times 10^{3}$ viruses remained infectious.

\section{Discussion}

In recent years, there have been many developments in indoor air treatment and bioaerosol microbial ecology. These have led to adaptations of equipment resulting in benefits for human health. We used the same experimental setup as in the study of Bandaly et al. (2017), which represents a real-life model of an airhandling unit. The same filter commonly used in AHUs (F7-Camfil EN779:2012) was employed; a filtration velocity of $0.16 \mathrm{~m} \mathrm{~s}^{-1}$ was applied, and the efficiency of the filtration was between 91 and $99 \%$. This effectiveness was verified in the study of Bailly (2001), which determined the air filter efficiency based on the four filtration phenomena curves. Adenovirus, a DNA respiratory virus measuring between 70 and $90 \mathrm{~nm}$, was chosen (Doerfler 1996). In this study, we carefully studied the molecular detection and infectivity up- and downstream of the filters and the dynamics and characteristics of the adenovirus in the system. The SMPS ${ }^{\mathrm{TM}}$ has a median electric mobility size $\left(d_{\mathrm{ae} .50}\right)$ of $87 \mathrm{~nm}$, close to the theoretical size of adenovirus described in the study of Doerfler (1996). According to the apoptotic phenomenon and the way in which adenovirus multiplies in the HEK-293 cell, we can propose some hypotheses about the virus aerosol. The particles detected by Q-PCR on the stages below the virus size may be DNA fragments because of the apoptosis effect that disrupted the cells (Green 2011). These disruptions may lead to autodegradation of the cell such as DNA degradation, which affected the DNA virus used in our study (Green 2011). The 
nebulized adenovirus could be aerosolized as a single virus or groups of viruses or could be associated with cell debris and proteins. This hypothesis corresponds to reality; the function of sneezing is to expel mucus containing irritants from the nasal cavity and microorganisms such as respiratory viruses (Cole and Cook 1998).

Based on Q-PCR and TCID $_{50}$ measurement for the quantification and detection of infectivity in the system, the study shows that adenovirus was stopped by the medium F7 filter, but some particles passed through the filters and remained infectious. A negligible loss of infectivity was detected, confirming the study of Davis et al. (1971) who showed that the maximum adenovirus survival occurred at a high relative humidity of up to $89 \%$. This RH value was observed in this experimental setup during the $25 \mathrm{~min}$ of aerosolization. The examined literature shows the presence of viruses on the filters of air treatment plants by molecular detection without any notion of the infectivity and fate of these viruses. The study of Goyal et al. (2011) did not detect any infectious viruses in used ventilation filters from two large public buildings, but they were able to detect viruses by PCR, while Farnsworth et al. (2006) showed the difficulty of detecting the persistence of viruses in AHUs since most viruses present on AHU filters are deactivated within a day.

Comparing this work with the study of Bandaly et al. (2017), there are morphologic and physiologic differences between adenovirus and mengovirus. Morphologically, adenovirus is a DNA virus with a size between 70 and $90 \mathrm{~nm}$ (Doerfler 1996), while mengovirus is an RNA virus with a smaller size between 22 and $30 \mathrm{~nm}$ (Faulkner et al. 1961). The physiologic differences are based on their multiplication in the host cells and their virulence. Adenovirus shows an apoptotic effect in the host cells, whereas mengovirus multiplication has a cytopathic effect. These different types of multiplication lead to different ways of virus release, as shown by comparing this work with the study of Bandaly et al. (2017) in which the initial viral solution had a greater cytopathic effect with mengovirus being released more easily with the bursting of cells than adenovirus in apoptotic cells. The study of Knight (1980) and the review of Gerba (2013) focused on the inactivation rate between respiratory viruses and showed that adenovirus has a low inactivation rate $\left(0.011 \log _{10} \mathrm{~h}^{-1}\right)$, whereas mengovirus, with a similar structure to rhinovirus, has a higher inactivation rate $\left(0.25 \log _{10} \mathrm{~h}^{-1}\right)$. These values are validated by comparing this work with the study of Bandaly et al. (2017), as adenovirus was more persistent in the system after aerosolization with a loss of $<1 \mathrm{log}$, but mengovirus showed a loss of $4 \log$ of infectivity.

According to Musher's review (2003), the oral secretions of people infected with adenovirus contain up to $10^{6}$ viruses per milliliter, which is in the same value range as the initial solution used in this work. Musher (2003) revealed that an adenovirus infective dose is equivalent to five viral particles for an adult. In this study, adenovirus was normalized per cubic meter of air, showing that $3.3 \times 10^{5}$ viruses $\mathrm{m}^{-3}$ passed through the filters and $1.6 \times 10^{3}$ viruses $\mathrm{m}^{-3}$ remained infectious during $25 \mathrm{~min}$ of aerosolization. In reality, an AHU blows or extracts $15 \mathrm{~m}^{3} \mathrm{~h}^{-1}$ per occupant and, to recover energy, in many office buildings up to $20 \%$ of the indoor air flow can be recycled. This concentration may spread the adenovirus back into the room and could infect the people present.

The major limitation of this study is that we used adenovirus from a cell culture, which is not representative of adenovirus that has been expelled from infected people, so one can suppose that the latter should be more persistent in AHUs. This has to be taken into account in studies of air recycling with the aim of economizing energy inside buildings.

\section{Conclusion}

Recent studies have tried to understand the gaps between the behavior of bacteria and fungi on filter media and the role of AHUs in the spread and transport of viral particles inside buildings. This study presents new information on the characterization and the behavior, etc., of adenovirus, a non-enveloped DNA respiratory virus, in indoor environments and its behavior in air treatment units. However, the evolution of air quality requirements (lack of biologic and hygienic quality) may lead to rethinking the principle of air recycling. These results are of major concern from a public health point of view, and policy makers have to take them into account to better protect public and human health. 
Acknowledgements This study was supported by the IMTAtlantique Bretagne-Pays de Loire and the École des Hautes Études de Santé Publique (EHESP). The authors are grateful to Prof. Christophe Gantzer from the LCPME, UMR 7564, Lorraine University (CNRS), France, for providing the adenovirus and the human embryonic kidney cells (HEK-293) and to Dr. Valérie Delague from the French Institute of Health and Medical Research (Inserm), UMR_S 910, Marseille, France, for providing the human embryonic kidney cells (HEK-293).

\section{References}

Aritake, S., Uchiyama, M., Tagaya, H., Suzuki, H., Kuriyama, K., Ozaki, A., et al. (2004). Time estimation during nocturnal sleep in human subjects. Neuroscience Research, 49(4), 387-393. https://doi.org/10.1016/j.neures.2004.04. 006.

Bailly, A. (2001). Traitement de l'air et Climatisation-Généralités." avril. http://www.techniques-ingenieur.fr/basedocumentaire/construction-et-travaux-publics-th3/lechauffage-la-climatisation-et-l-eau-chaude-sanitaire42582210/traitement-de-1-air-et-climatisation-be9270/. Accessed 10 Apr 2001.

Bandaly, V., Joubert, A., Le Cann, P., \& Andres, Y. (2017). The fate of mengovirus on fiberglass filter of air handling units. Food and Environmental Virology. https://doi.org/10. 1007/s12560-017-9310-8.

Bluyssen, P. M., Cox, C., Seppänen, O., de Oliveira Fernandes, E., Clausen, G., Müller, B., et al. (2003). Why, when and how do HVAC-systems pollute the indoor environment and what to do about it? The European AIRLESS project. Building and Environment, 38(2), 209-225. https://doi.org/ 10.1016/S0360-1323(02)00058-6.

Cole, E. C., \& Cook, C. E. (1998). Characterization of infectious aerosols in health care facilities: An aid to effective engineering controls and preventive strategies. American Journal of Infection Control, 26(4), 453-464. https://doi. org/10.1016/S0196-6553(98)70046-X.

Couch, R. B., Cate, T. R., Jr Douglas, R. G., Gerone, P. J., \& Knight, V. (1966). Effect of route of inoculation on experimental respiratory viral disease in volunteers and evidence for airborne transmission. Bacteriological Reviews, 30(3), 517-529.

Davis, G. W., Griesemer, R. A., Shadduck, J. A., \& Farrell, R. L. (1971). Effect of relative humidity on dynamic aerosols of adenovirus 12. Applied Microbiology, 21(4), 676-679.

Doerfler, W. (1996). Adenoviruses. In S. Baron (Ed.), Medical microbiology, 4th ed. Galveston (TX): University of Texas Medical Branch at Galveston. http://www.ncbi.nlm.nih. gov/books/NBK8503/.

Douwes, J., Thorne, P., Pearce, N., \& Heederik, D. (2003). Bioaerosol health effects and exposure assessment: Progress and prospects. Annals of Occupational Hygiene, 47(3), 187-200. https://doi.org/10.1093/annhyg/meg032.

Downie, A. W., Meiklejohn, M., St Vincent, L., Rao, A. R., Sundara Babu, B. V., \& Kempe, C. H. (1965). The recovery of smallpox virus from patients and their environment in a smallpox hospital. Bulletin of the World Health Organization, 33(5), 615-622.

EN1822 (European Norme) Par Camfil. (2017). Accessed April 10. http://www.camfil.fr/Technique-de-filtration/ Specifications-industrielles/EN-1822/.

EN779:2012 (Filtration Norme). (2017). Accessed April 10. http://www.camfil.fr/Technique-de-filtration/ Specifications-industrielles/EN779_2012/.

Ezratty, V., \& Squinazi, F. (2008). Pandemic influenza virus inside buildings: Is there a risk of transmission by ventilation or air conditioning systems? Environnement, Risques \& Santé, 7(4), 255-263. https://doi.org/10.1684/ers. 2008.0157.

Fabian, P., McDevitt, J. J., DeHaan, W. H., Fung, R. O. P., Cowling, B. J., Chan, K. H., et al. (2008). Influenza virus in human exhaled breath: An observational study. PLOS ONE, 3(7), e2691. https://doi.org/10.1371/journal.pone. 0002691.

Fabian, P., Milton, D., Angel, M., Perez, D., \& McDevitt, J. (2011). Influenza virus aerosols in human exhaled breath: Particle size, culturability, and effect of surgical masks. Epidemiology, 22(1), S51. https://doi.org/10.1097/01.ede. 0000391818.35353.36.

Farnsworth, J. E., Goyal, S. M., Kim, S. W., Kuehn, T. H., Raynor, P. C., Ramakrishnan, M. A., et al. (2006). Development of a method for bacteria and virus recovery from heating, ventilation, and air conditioning (HVAC) filters. Journal of Environmental Monitoring: JEM, 8(10), 1006-1013.

Faulkner, P., Martin, E., Sved, S., Valentine, R., \& Work, T. (1961). Studies on protein and nucleic acid metabolism in virus-infected mammalian cells. 2 . The isolation, crystallization and chemical characterization of mouse encephalomyocarditis virus. Biochemical Journal, 80(3), 597-605. https://doi.org/10.1042/bj0800597.

Faure, M. (2010). Purification de l'air Ambiant Par l'Action Bactericide de la Photocatalyse. Lorraine: Ecole doctorale RP2E.

Gerba, C. P. (2013). Occurrence and transmission of food- and waterborne viruses by fomites. Virus in Food and Water. https://doi.org/10.1533/9780857098870.3.205.

González, L. F., Joubert, A., Andrès, Y., Liard, M., Renner, C., \& Le Coq, L. (2016). Filtration performances of HVAC filters for PM10 and microbial aerosols-Influence of management in a lab-scale air handling unit. Aerosol Science and Technology, 50(6), 555-567. https://doi.org/10. 1080/02786826.2016.1167833.

Goyal, S. M., Anantharaman, S., Ramakrishnan, M. A., Sajja, S., Kim, S. W., Stanley, N. J., et al. (2011). Detection of viruses in used ventilation filters from two large public buildings. American Journal of Infection Control, 39(7), e30-e38. https://doi.org/10.1016/j.ajic.2010.10.036.

Green, D. R. (2011). Means to an end: Apoptosis and other cell death mechanisms. New York: Cold Spring Harbor Laboratory Press.

Jones, A. P. (1999). Indoor air quality and health. Atmospheric Environment, 33(28), 4535-4564. https://doi.org/10.1016/ S1352-2310(99)00272-1.

Klepeis, N. E., Nelson, W. C., Ott, W. R., Robinson, J. P., Tsang, A. M., Switzer, P., et al. (2001). The National Human Activity Pattern Survey (NHAPS): A resource for 
assessing exposure to environmental pollutants. Journal of Exposure Science \& Environmental Epidemiology, 11(3), 231-252. https://doi.org/10.1038/sj.jea.7500165.

Knight, V. (1980). Viruses as agents of airborne contagion. Annals of the New York Academy of Sciences, 353(1), 147-156. https://doi.org/10.1111/j.1749-6632.1980. tb18917.x.

Lowen, A. C., Mubareka, S., Steel, J., \& Palese, P. (2007). Influenza virus transmission is dependent on relative humidity and temperature. PLoS Pathogens, 3(10), 1470-1476. https://doi.org/10.1371/journal.ppat.0030151.

Miller, F. N., Toohey, D., \& Zhai, J. (2017). Ultrafine and fine particulate matter inside and outside of mechanically ventilated buildings. International Journal of Environmental Research and Public Health, 2017(14), 128. https:// doi.org/10.3390/ijerph14020128.

Morawska, L. (2006). droplet fate in indoor environments, or can we prevent the spread of infection? Indoor Air, 16(5), 335-347. https://doi.org/10.1111/j.1600-0668.2006. 00432.x.

Musher, D. M. (2003). How contagious are common respiratory tract infections? The New England Journal of Medicine, 348(13), 1256-1266. https://doi.org/10.1056/ NEJMra021771.

Myatt, T. A., Johnston, S. L., Zuo, Z. F., Wand, M., Kebadze, T., Rudnick, S., et al. (2004). Detection of airborne rhinovirus and its relation to outdoor air supply in office environments. American Journal of Respiratory and Critical Care Medicine, 169(11), 1187-1190. https://doi.org/10.1164/ rccm.200306-760OC.

Prussin, A. J., Vikram, A., Bibby, K. J., \& Marr, L. C. (2016). Seasonal dynamics of the airborne bacterial community and selected viruses in a children's daycare center. PLoS ONE, 11(3), e0151004. https://doi.org/10.1371/journal. pone. 0151004 .
Ramakrishnan, M. A. (2016). Determination of $50 \%$ endpoint titer using a simple formula. World Journal of Virology, 5(2), 85-86. https://doi.org/10.5501/wjv.v5.i2.85.

Ryu, H., Cashdollar, J. L., Shay Fout, G., Schrantz, K. A., \& Hayes, S. (2015). Applicability of integrated cell culture quantitative PCR (ICC-QPCR) for the detection of infectious adenovirus type 2 in UV disinfection studies. Journal of Environmental Science and Health, Part A, 50(8), 777-787. https://doi.org/10.1080/10934529.2015. 1019795.

Seppänen, O. A., \& Fisk, W. J. (2004). Summary of human responses to ventilation. Indoor Air, 14, 102-118. https:// doi.org/10.1111/j.1600-0668.2004.00279.x.

Siegel, J. M. (2003). Why we sleep. Scientific American, 289(5), 92-97.

Tang, J. W., Li, Y., Eames, I., Chan, P. K. S., \& Ridgway, G. L. (2006). Factors involved in the aerosol transmission of infection and control of ventilation in healthcare premises. Journal of Hospital Infection, 64(2), 100-114. https://doi. org/10.1016/j.jhin.2006.05.022.

Tellier, R. (2006). Review of aerosol transmission of influenza a virus. Emerging Infectious Diseases, 12(11), 1657-1662. https://doi.org/10.3201/eid1211.060426.

Turcotte, M. (2005). Time spent with family during a typical workday, 1986 to 2005. Canadian Social Trends. http:// www.statcan.gc.ca/pub/11-008-x/2006007/9574-eng.htm.

Zhao, A. P., \& Stephens, B. (2015). Evaluating the long-term health and economic impacts of central residential air filtration for reducing premature mortality associated with indoor fine particulate matter (PM2.5) of outdoor origin. International Journal of Environmental Research and Public Health, 12, 8448-8479. https://doi.org/10.3390/ ijerph120708448.

Zheng, Y., \& Yao, M. (2017). Liquid impinger BioSampler's performance for size-resolved viable bioaerosol particles. Journal of Aerosol Science, 106(April), 34-42. https://doi. org/10.1016/j.jaerosci.2017.01.003. 